\title{
Intraoperative ultrasound imaging of coronary artery ostial stenosis
}

Taiju Watanabe, MD, Hirokuni Arai, MD, PhD, and Tomohiro Mizuno, MD, $\mathrm{PhD}$

From the Department of Cardiovascular Surgery, Tokyo Medical and Dental University Graduate School of Medical and Dental Sciences, Tokyo, Japan.

Disclosures: Authors have nothing to disclose with regard to commercial support.

Received for publication Dec 3, 2014; accepted for publication Dec 3, 2014; available ahead of print Jan 13, 2015.

Address for reprints: Hirokuni Arai, MD, PhD, Department of Cardiovascular Surgery, Tokyo Medical and Dental University Graduate School of Medical and Dental Sciences, 1-5-45 Yushima Bunkyo-ku Tokyo 113-8519, Japan (E-mail: hiro.cvsg@tmd.ac.jp).

J Thorac Cardiovasc Surg 2015;149:1206-7

$0022-5223 / \$ 36.00$

Copyright $(\odot) 2015$ by The American Association for Thoracic Surgery

http://dx.doi.org/10.1016/j.jtcvs.2014.12.005

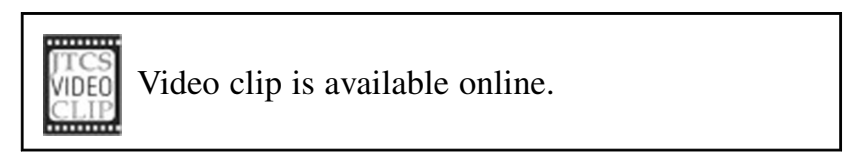

A 72-year-old man with symptomatic severe aortic valve stenosis underwent aortic valve replacement. Preoperatively, transient systemic hypotension was detected via coronary angiography during right coronary artery (RCA) ostial engagement. Thus, RCA ostial stenosis was suspected; however, it was difficult to identify the ostial lesion on angiography (Figure 1).

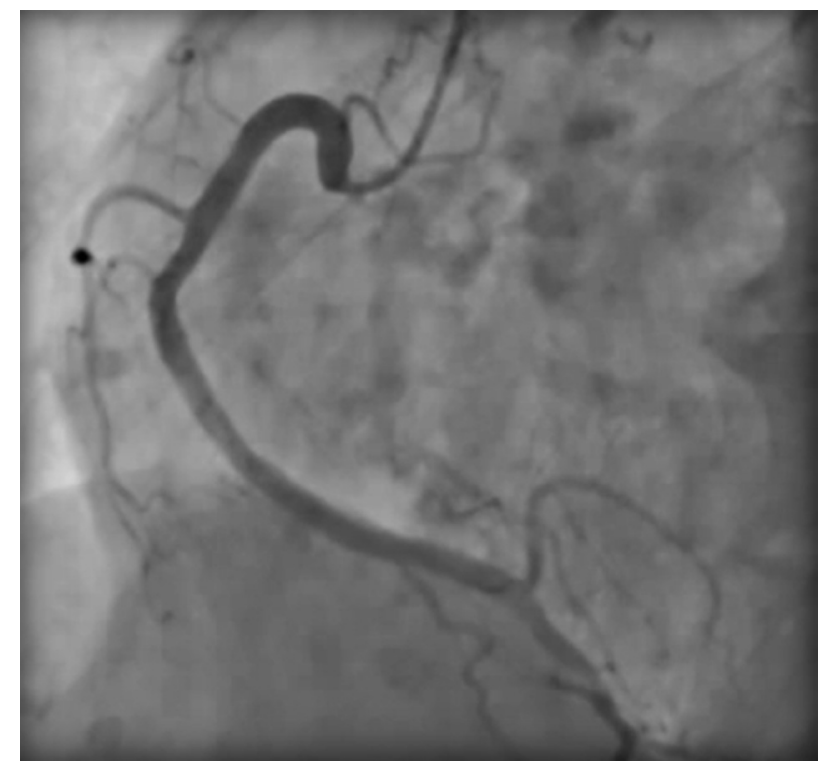

FIGURE 1. Angiographic findings in the RCA.
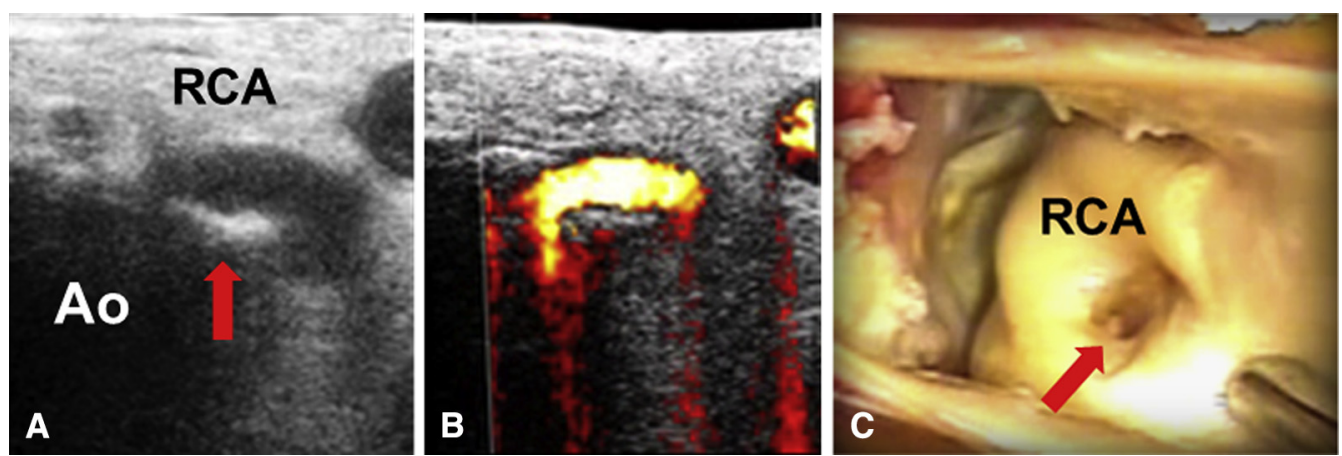

FIGURE 2. High-frequency ECUS indicating the mobile calcified plaque (A, arrow) and the restricted inflow on color Doppler flow maps (B) at the RCA ostium. C, The plaque at the RCA ostium (arrow) was confirmed under direct vision after the aortotomy. Ao, Aorta; RCA, right coronary artery. 
Intraoperatively, we used a $15-\mathrm{MHz}$ high-frequency epicardial ultrasound (ECUS) (VeriQ C system; Medistim, Oslo, Norway) to evaluate the RCA ostial lesion. ECUS successfully identified a mobile calcified plaque (Figure 2, A, and Video 1) and restricted inflow on color Doppler flow maps at the RCA ostium (Figure 2, B). After the aortic root was incised, the presence of the plaque at the RCA ostium was confirmed under direct vision
(Figure 2, C). Coronary artery bypass grafting to the RCA was performed concomitantly. However, if the case had involved an isolated coronary artery bypass graft or another cardiac surgery not requiring aortotomy, the coronary ostial stenosis could have been missed. When RCA ostial stenosis is suspected preoperatively, intraoperative ECUS can be useful for confirming the lesion, thus enhancing the safety of cardiac surgery. 